\title{
Concepciones de ciencia desde la perspectiva de diversidad cultural en profesores de programas de licenciaturas en ciencias naturales y educación ambiental en Colombia*
}

\author{
[Artículos]
}

\author{
Juan David Adame Rodríguez ${ }^{* *}$
}

Recibido: 10/09/2020

Aprobado: 26/11/2020

Citar como:

Adame, J. (2021). Concepciones de ciencia desde la perspectiva de diversidad cultural en profesores de programas de Licenciatura en Ciencias Naturales y Educación Ambiental en Colombia. Análisis, 53(98).

https://doi.org/10.15332/21459169.6130

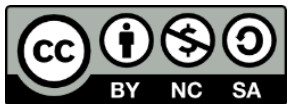

\footnotetext{
* Artículo de investigación científica y de desarrollo tecnológico. Producto de la Tesis Doctoral titulada "Concepciones de ciencia desde la perspectiva de diversidad cultural en profesores de Programas de Licenciatura en Ciencias Naturales y Educación Ambiental en Colombia". Doctorado interinstitucional en Educación, énfasis Educación en Ciencias. Universidad Distrital Francisco José de Caldas.

** Candidato a Doctor en Educación. Doctorado Internisititucional en Eduación. Énfasis Educacion en Ciencias. Universidad Distrital Francisco José de Caldas. Grupo de Investigación Didaquim. Correo electrónico: bioadame@gmail.com; ORCID: https://orcid.org/0000-0001-5626-0694
} 


\section{Resumen}

La ciencia occidental pareciera verse como único fin de la enseñanza de la educación científica. Esta situación visiviliza una de las principales dificultades en la formación de un profesorado que se circunscribe ante una diversidad de saberes arraigados a una nación pluriétnica y multicultural como la nuestra. Este artículo presenta los resultados de investigación de la tesis doctoral Concepciones de ciencia desde la perspectiva de diversidad cultural en profesores de licenciatura en ciencias naturales y educación ambiental en Colombia. Inicialmente, expone tendencias actuales relacionadas con las concepciones de ciencia presentes en el profesorado desde el marco de la diversidad cultural y su relación con la enseñanza. Posteriormente, describe un cuerpo metodológico que, desde el diseño y validación de dos instrumentos (situaciones en contexto y cuestionarios sobre representaciones de contenido), permitió analizar el objeto de investigación en docentes y documentos maestros de tres programas de formación inicial de profesores, distribuidos en tres regiones diferenciadas culturalmente del país. Finalmente, se encuentra en la epistemología universalista un eje fundante que sobresale en la formación del profesorado en ciencias en nuestro territorio.

Palabras clave: concepciones de ciencia, diversidad cultural, formación inicial de profesores, ciencias naturales y educación ambiental.

\section{Conceptions of science from the perspective of cultural diversity in teachers of bachelor's degree programs in natural sciences and environmental education in Colombia}

\section{Abstract}

Western science seems to be seen as the sole purpose of science education teaching. This situation envisions one of the main difficulties in the training of teachers that is circumscribed by a diversity of 
knowledge rooted in a multiethnic and multicultural nation as ours. This article presents the research results of the doctoral thesis "Conceptions of science from the perspective of cultural diversity in teachers of bachelor's degree programs in natural sciences and environmental education in Colombia”. Initially, it exposes current trends related to the conceptions of science existing in teachers from the framework of cultural diversity and its relationship with teaching. Subsequently, it describes a methodological body that, from the design and validation of two instruments (situations in context and questionnaires on content representations), allowed to analyze the object of research in teachers and master documents of three initial teacher training programs distributed in three culturally differentiated regions of the country. Finally, the universalist epistemology is found as a fundamental aspect that stands out in the training of science teachers in our territory.

Keywords: Conceptions of science, cultural diversity, initial teacher training, natural sciences and environmental education.

\section{Concepções da ciência a partir da perspectiva da diversidade cultural em professores de programas de licenciaturas em ciências naturais e educação ambiental na Colômbia}

\section{Resumo}

A ciência ocidental parece ser vista como o único fim do ensino de educação científica. Essa situação visibiliza uma das principais dificuldades na formação de um professor que está cercado por uma diversidade de conhecimento enraizada numa nação multiétnica e multicultural como a nossa. Este artigo apresenta os resultados da tese de doutorado Concepções da ciência a partir da perspectiva da diversidade cultural em professores de licenciatura em ciências naturais e educação ambiental na Colômbia. Inicialmente, expõe tendências atuais relacionadas às concepções de ciência presentes em professores a partir do quadro da diversidade cultural e sua relação com 
o ensino. Posteriormente, descreve um corpo metodológico ideal que, a partir da concepção e validação de dois instrumentos (situações em contexto e questionários sobre representação deconteúdo), permitiu a análise do objeto de pesquisa em professores e documentos mestres de três programas iniciais de formação de profesores, distribuídos em três regiões culturalmente diferenciadas do país. Finalmente, há na epistemologia universalista um eixo fundador que se destaca na formação de professores em ciências em nosso território.

Palavras-chave: concepções de ciência, diversidade cultural, formação inicial de professores, ciências naturais e educação ambiental.

\section{Introducción}

Los países latinoamericanos viven una marcada tendencia cultural hegemónica y homogeneizante, o sea, una tendencia a la occidentalización del mundo, que día a día conduce a la pérdida de la identidad cultural y la diversidad cultural en países multiculturales y pluriétnicos. Estos terminan influenciados por la imposición de modelos económicos, políticos y educativos que generan el detrimento de diversas costumbres, saberes y tradiciones que constituyen y fundamentan la base de estas sociedades (García, 2004).

En relación con lo anterior, la ciencia occidental pareciera verse como único fin de la educación científica (Vázquez et ál., 2001). En este aspecto podría emerger una de las principales problemáticas contemporáneas de la enseñanza de las ciencias y la formación de su profesorado (Sepúlveda y El-Hani, 2004), pues el aula se concibe como un espacio heterogéneo y el acto educativo se consolida a través de la diversidad. Esto conduce a replantear su imagen a través de las diferentes concepciones arraigadas a creencias, cosmovisiones, cosmogonías o epistemologías propias del estudiantado (Sánchez-Arteaga et ál., 2013). Conforme a lo descrito, la siguiente es la pregunta que orienta la investigación: ¿cuáles son las 
concepciones de ciencia desde la perspectiva de la diversidad cultural en profesores de programas de formación inicial de licenciados en ciencias naturales y educación ambiental en tres regiones de Colombia?

Uno de los principales retos que debe afrontar los programas de formación inicial de profesores subyace en la adaptación del currículo escolar a la diversidad cultural (Nuñez, 2009). En relación con lo anterior, el docente en formación debe reconocer la diversidad cultural no solo como una característica de la sociedad que le permite apreciar y comprender la heterogeneidad entre individuos, sino como una oportunidad de enriquecer su desarrollo conceptual y discurso educativo (Molina, 2010). Adicionalmente, debe apoyarse desde la investigación en la didáctica de las ciencias para el diseño, formulación y reestructuración de metodologías, procedimientos y estrategias de enseñanza, que favorezcan procesos de conceptualización más complejos, con el fin de permitir la contextualización de diferentes conocimientos, saberes y prácticas científicas en entornos únicos y específicos, delimitados por dimensiones políticas, económicas, sociales y culturales. De esta manera, se favorece la reestructuración de la imagen de ciencia (Garay, 2011).

A través de esta investigación, se abordó el análisis de las concepciones de ciencia desde la perspectiva de diversidad cultural en la enseñanza, a partir de enfoques epistemológicos, antropológicos, didácticos de las ciencias y sociológicos del conocimiento científico. A su vez, se describió e interpretó las concepciones de ciencia desde la diversidad cultural en profesores(as) de programas de formación inicial de licenciados de ciencias naturales y educación ambiental en Colombia. 


\section{Tendencias contemporáneas sobre concepciones de ciencia desde la perspectiva de diversidad cultural en profesores de ciencias naturales}

Desde la educación contemporánea en ciencias, autores como Cobern y Loving (2001), y Molina et ál. (2004) reflexionan sobre la importancia de empoderar diversas posturas que difieran meramente de los conocimientos científicos para explicar fenómenos de la naturaleza, teniendo en cuenta la gran diversidad cultural presente desde los diferentes contextos que enfrenta el maestro en sus aulas de clase.

De esta forma, podemos encontrar que la enseñanza y aprendizaje de las ciencias de la naturaleza es considerada cada vez más como un proceso cultural, en el cual confluyen varias culturas y sus correspondientes sistemas de conocimiento (Molina y Utges, 2011). Entonces, como parte de las investigaciones en educación científica y en relación con el conocimiento escolar desde las concepciones de ciencia con una perspectiva de la diversidad cultural, se pueden establecer las siguientes cinco tendencias, a partir de Molina et ál. (2009), y Molina y Mojica (2013): universalismo, multiculturalismo, pluralismo epistemológico, interculturalismo y contextualismo cultural.

Southerland (2000) sostiene una postura universalista, en la medida en que manifiesta que la ciencia posee un cuerpo de conocimientos y un campo de acción de carácter universal. Así, esta no puede ser enseñada desde una perspectiva multicultural, debido, según como afirma Siegel (1997), al poder epistémico superior presente de la ciencia moderna occidental en relación con otras formas de conocimiento.

Por otra parte, Ogawa (1995) propone una visión multiculturalista al introducir en la enseñanza de las ciencias una reflexión acerca del estudio de un conocimiento tradicional ecológico (TEK), que reconoce la importancia de conocimientos ancestrales y tradicionales presentes en la 
diversidad cultural, con lo que, en contraposición, actúa la postura universalista desde el punto de vista epistemológico, moral y político. En este mismo sentido, autores como Kawagley et ál. (1998) defienden el concepto de 'ciencia' teniendo en cuenta otros saberes que también tienen validez; es decir, las ciencias modernas se pueden enriquecer a partir de diferentes visiones presentes desde la pluralidad y diversidad cultural, con el fin de comprender fenómenos naturales y el mundo desde un panorama más integral.

Los pluralistas epistemológicos como El-Hani y Bizzo (1999) reconocen la importancia del conocimiento científico como uno de los pilares de la educación científica, pero no desconocen otros tipos de conocimientos de carácter ancestral o tradicional que pueden estar arraigados en los procesos de enseñanza-aprendizaje presentes en el aula. Cobern y Loving (2001) argumentan que, debido al marcado cientificismo existente en nuestras sociedades, se ha dejado de dar la importancia que se merece a otras formas de conocimiento que pueden provenir del arte, la literatura $o$ la religión.

Autores como Molina y Utges (2011) sostienen una postura orientada a la interculturalidad, cuyo intercambio entre conocimientos de orígenes culturales diversos puede favorecer a superar problemáticas desde la didáctica de las ciencias y donde las concepciones de enseñanza del profesorado asumen exclusivamamente una postura cientificista.

Por otra parte, los contextualistas culturales plantean que la ciencia debe entenderse desde contextos culturales específicos, lo cual redunda en un proceso de enseñanza-aprendizaje más próximo a las necesidades escolares presentes en la educación científica (García, 2004). 


\section{Metodología}

\section{Población objeto de estudio}

Esta investigación se realizó con programas de formación inicial de profesores de ciencias naturales y educación ambiental en Colombia (licenciaturas, tal y como se denominan estos programas en concordancia con lo establecido en la Ley 30 de 1992 y en la Ley 115 de 1994). No obstante, solo se tuvieron en cuenta aquellos programas que se encontraban activos y tenían a la fecha registro calificado por parte del Ministerio de Educación Nacional (MEN). Dentro de los reportes registrados se tuvieron en cuenta todos los programas que presentaran un objeto de formación similar u homologable registrados ante el Sistema Nacional de Información de la Educación Superior (SNIES).

\section{Muestra}

Al momento de seleccionar la muestra, 34 programas de licenciatura estaban suscritos bajo las denominaciones descritas y cumplían con las características mencionadas en el punto anterior. Eran ofertados por 22 universidades ( 15 oficiales y 7 privadas) en un total de 24 municipios; 29 de ellos se orientan en modalidad presencial y 5 a distancia. De este total, se priorizaron para esta investigación tres, los cuales se describen en la tabla 1.

Tabla 1. Programas de educación superior objeto de estudio (casos)

\begin{tabular}{|l|l|l|l|l|}
\hline Región & \multicolumn{1}{|c|}{ Universidad } & \multicolumn{1}{c|}{ Programa } & Modalidad & \multicolumn{1}{|c|}{$\begin{array}{c}\text { N. }{ }^{\circ} \text { de } \\
\text { docentes }\end{array}$} \\
\hline Caribe & $\begin{array}{l}\text { Universidad de } \\
\text { Córdoba }\end{array}$ & $\begin{array}{l}\text { Licenciatura en } \\
\text { Ciencias Naturales y } \\
\text { Educación Ambiental }\end{array}$ & Presencial & 1 \\
\hline Centro & $\begin{array}{l}\text { Universidad } \\
\text { Pedagógica y }\end{array}$ & $\begin{array}{l}\text { Licenciatura en } \\
\text { Ciencias Naturales y } \\
\text { Educación Ambiental } \\
\text { profesional }\end{array}$ & Presencial & 1 \\
\hline
\end{tabular}




\begin{tabular}{|c|c|c|c|c|}
\hline Región & Universidad & Programa & Modalidad & $\begin{array}{c}\text { N. }{ }^{\circ} \text { de } \\
\text { docentes }\end{array}$ \\
\hline & $\begin{array}{l}\text { Tecnológica de } \\
\text { Colombia }\end{array}$ & & & $\begin{array}{l}\text { Práctica } \\
\text { profesional }\end{array}$ \\
\hline \multirow[t]{2}{*}{ Pacífco } & $\begin{array}{l}\text { Universidad del Valle } \\
\text { (sede Buenaventura) }\end{array}$ & $\begin{array}{l}\text { Licenciatura en } \\
\text { Ciencias Naturales y } \\
\text { Educación Ambiental }\end{array}$ & Presencial & $\begin{array}{l}1 \\
\text { Práctica } \\
\text { profesional }\end{array}$ \\
\hline & $\begin{array}{l}\text { Universidad del valle } \\
\text { (sede Cali) }\end{array}$ & $\begin{array}{l}\text { Licenciatura en } \\
\text { Ciencias Naturales y } \\
\text { Educación Ambiental }\end{array}$ & Presencial & $\begin{array}{l}1 \\
\text { Práctica } \\
\text { profesional }\end{array}$ \\
\hline
\end{tabular}

Fuente: elaboración propia.

\section{Ubicación del área de estudio}

Esta investigación buscó cubrir el territorio nacional. Teniendo en cuenta las diversas características culturales que tiene nuestro país, se tomó como referente los trabajos antropológicos de Gutiérrez de Pineda (1975) y la investigación de Molina et ál. (2014), quienes circunscriben la población colombiana en ocho regiones conforme a sus características étnicas y sociales: región Andina central, región Andina meridional, región santandereana, región paisa, región fluviominera Caribe, región fluviominera del valle alto del Magdalena, región fluviominera del valle medio del Magdalena, región fluviominera Pacífica valluna y región fluviominera Pacífica costera

Es de resaltar que, conforme a los registros obtenidos por parte del Sistema Nacional de Información para la Educación Superior en Colombia (SNIES), los programas de licenciatura en ciencias naturales y educación ambiental no son ofertados en las regiones oriental, amazónica e insular. Por tal razón, dichos lugares no fueron tenidos en cuenta para esta investigación (figura 1). 
Figura 1. Estudio de caso múltiple y su ubicación por región (Licenciatura en Ciencias Naturales y Educación Ambiental)

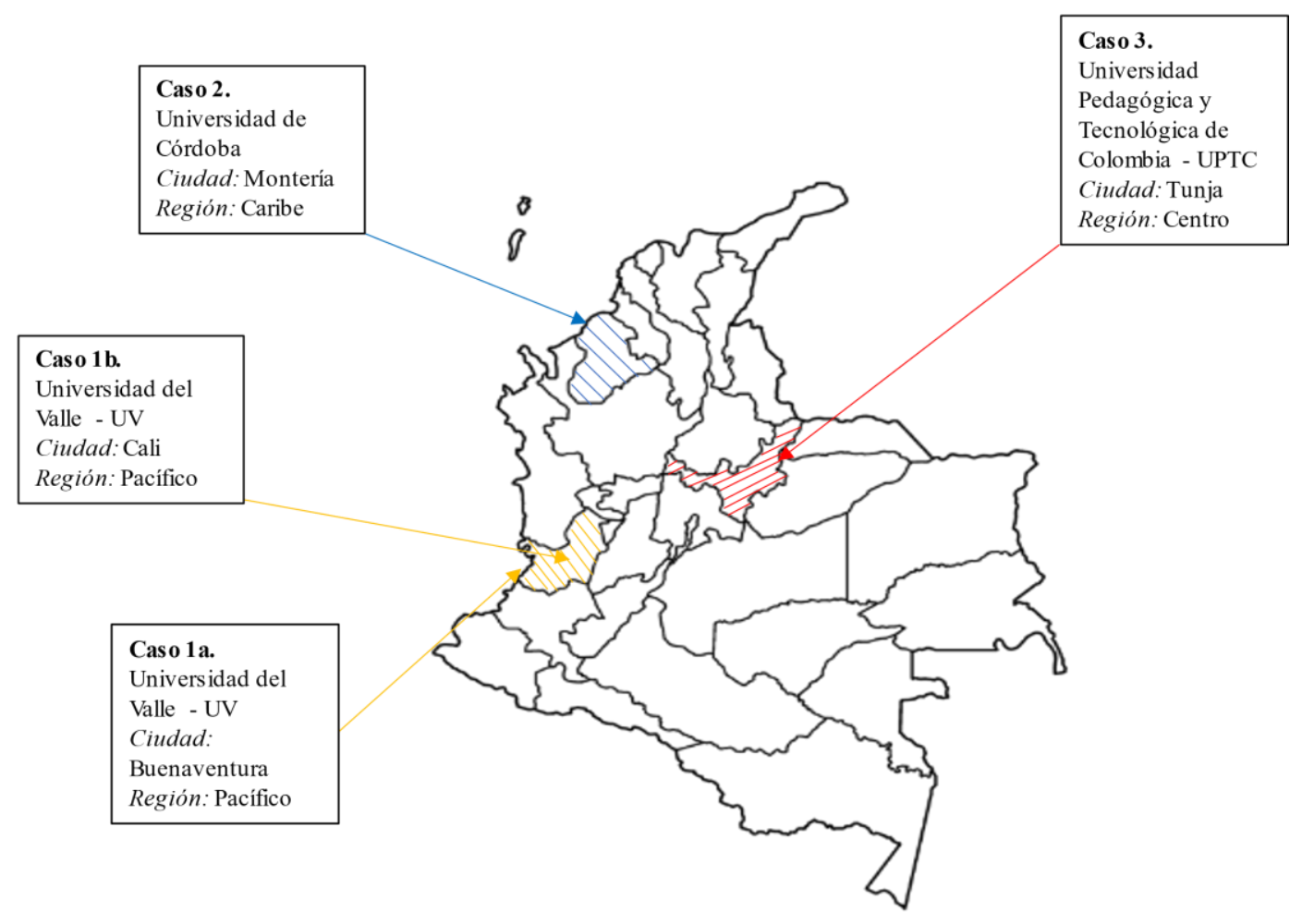

Fuente: elaboración propia.

\section{Enfoque investigativo}

Se diseñó una puesta metodológica posicionada desde el paradigma de investigación cualitativa hermenéutica. El método de investigación se abordó desde un diseño sistemático que parte de una codificación abierta, la cual definió las categorías de la pesquisa.

Para el caso de esta investigación, se diseñó un método enfocado a través del estudio de casos múltiples, con el fin de abarcar el territorio nacional. Se diseñaron y validaron con expertos dos instrumentos de intervención (grupo Intercitec, Universidad Distrital Francisco Jóse de Caldas; grupo Didaquím, Univiersidad Distrital Francisco Jóse de Caldas; grupo Didacies, Universitat de València; grupo Gepic, Universidade Federal do 
Triângulo Mineiro - UFTM), con el fin de recabar información a partir de entrevistas a docentes y documentos maestros de las licenciaturas en estudio, por medio de situaciones en contexto y cuestionario sobre representaciones de contenido $(\mathrm{ReCo})$.

Se establecieron cinco dimensiones las cuales se definieron como categorías sistemáticas (dimensión educativa, dimensión político-escolar, dimensión histórica, dimensión diversidad epistémica y dimensión intercultural). Estas se cruzaron con una hipótesis de progresión de las diferentes epistemologías docentes encontradas desde la educación científica sobre la diversidad cultural, producto del rastreo de la información en circulación especializada (universalistas, pluralistas epistémicas, multiculturalistas, interculturalistas y contextualistas culturales).

A partir del discurso narrativo de los docentes y de los documentos entrevistados, se obtuvieron las transcripciones que fueron tratadas por medio de la estrategia de análisis de contenido, en donde las unidades muestrales fueron trianguladas a partir de las categorías propuestas (diseño sistemático) e hipótesis de progresión. Se hicieron redes semánticas y tablas de coocurrencia a partir del programa ATLAS.ti v8 (figura 2).

\section{Instrumentos}

Para este tipo de estudio, se formularon dos instrumentos que, sobre las mismas preguntas a los distintos casos, realizaron una interpretación de las respuestas dentro criterios de validez aceptados en este tipo de investigaciones (Guba y Licoln, 1994). Lo anterior, para llegar a conclusiones que permitieron identificar concepciones sobre las ciencias y sus posibles relaciones con la cultura y su diversidad en docentes de 
programas de formación incial en ciencias naturales y educación ambiental. Los diseños de los instrumentos de intervención se estructuraron desde su protocolo a partir de dos enfoques conforme al objeto de estudio de la investigación. Se basó en dos tipos de entrevistas: la primera, de tipo semiestructurada, a través de situaciones en contexto Molina et ál. (2014); la segunda, a través de un cuestionario abierto, con preguntas orientadoras (Cuestionario ReCo).

Con el fin de conocer las concepciones presentes de los docentes entrevistados, se aplicó el primer tipo de instrumento. Este correspondió a las diferentes categorías sistemáticas propuestas para esta investigación (dimensiones) que, a través del desarrollo de diferentes situaciones (Molina et ál., 2014), fueron cruzadas con una tendencia de progresión de las epistemologías presentes encontradas desde la educación en ciencias. 
Figura 2. Fundamentación del diseño metodológico de investigación

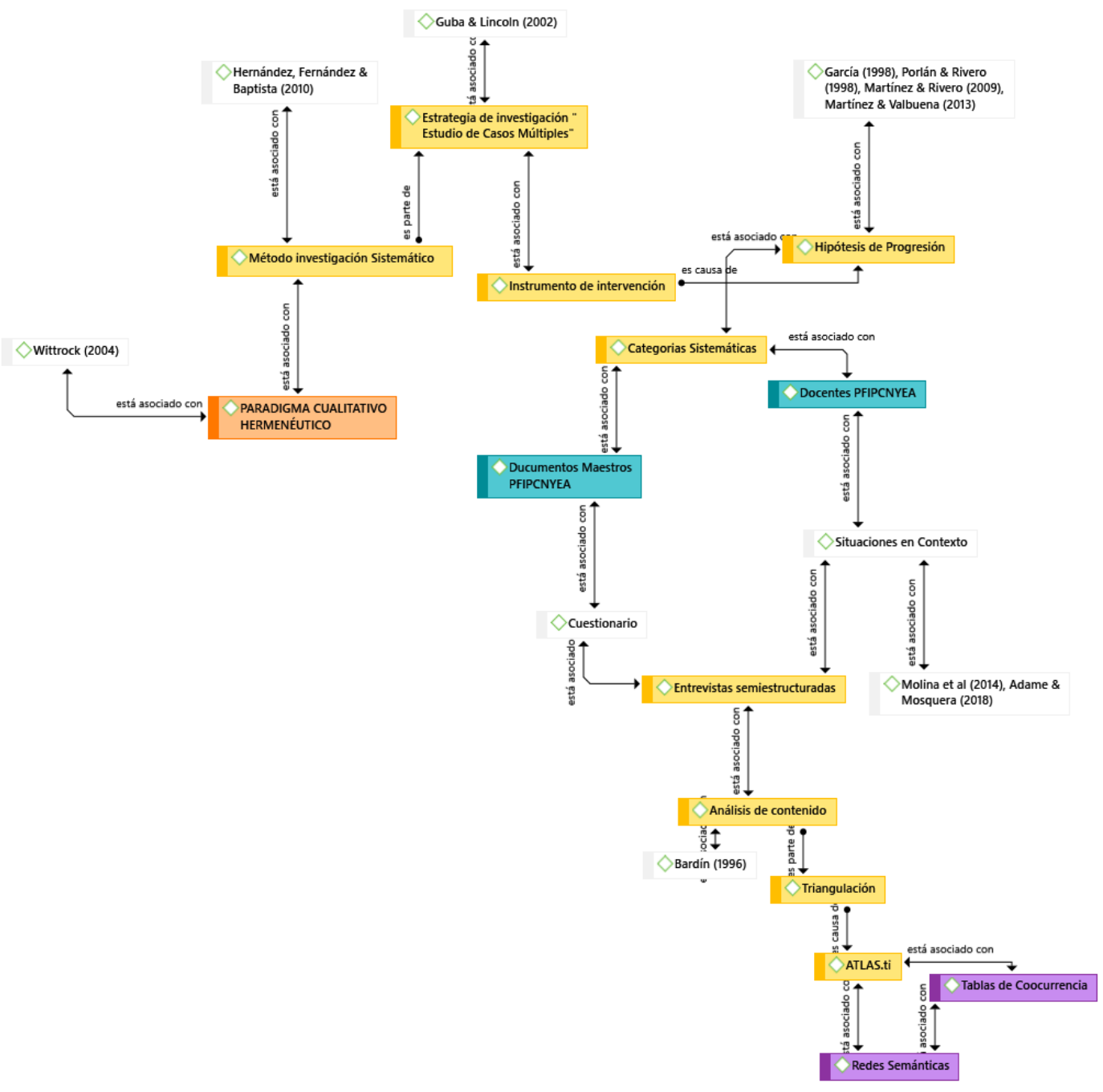

Fuente: elaboración propia.

En relación con lo anterior, es de resaltar que la hipótesis de progresión (HdP) surge como una alternativa en el proceso de organización del conocimiento, que favorece su comprensión a través de una construcción paulatina y gradual. En dichas hipótesis se asume el conocimiento como una transformación conceptual que parte de concepciones simples (intuitivas o poco elaboradas) hasta alcanzar concepciones más complejas, fruto de la reflexión, la experiencia y la investigación (Porlan et ál., 1998; 
Martínez y Molina, 2011). De esta manera, se van determinando cambios conceptuales cuya diferenciación sirve de marco de referencia y de orientación en los procesos dinámicos de enseñanza y aprendizaje (Martinez y Rivero, 2005).

\section{Dimensiones de la investigación}

\section{Dimensión histórica}

Se enfoca en las contribuciones que pueden hacer la historia a la formación del profesorado de ciencias desde la diversidad cultural. Esas contribuciones incluyen la mejora del conocimiento de los contenidos, la aportación de una componente cultural al currículo, la identificación de obstáculos de aprendizaje en el estudiantado, herramientas para el diseño de unidades didácticas y una plataforma general de actitudes y valores sobre la ciencia (Adúriz, 2010).

A su vez, es imprescindible reconocer cuál ha sido la influencia en procesos de enseñanza y aprendizaje en aspectos como el cientifisismo, el racismo científico, la violencia epistémica, el epistemicidio y la homogenización del saber. Todo esto ha sido sucitado ante grandes movimientos mundiales como el colonialismo, la modernidad o la misma globalización (De Sousa Santos, 2009; Molina et ál., 2014; Pulido, 2009; Uribe, 2019).

\section{Dimensión intercultural}

Es definida como el intercambio cultural en el espacio escolar, a través de la diferencia entre los diversos contextos culturales y la oferta educativa. Puede ser vista también desde la heterogeneidad regional y la desigualdad educativa. La enseñanza de las ciencias en escenarios interculturales implica "el intercambio, la negociación, la construcción y reconstrucción de significados" (Hongming, 2009). El aula de ciencias naturales, vista desde la perspectiva intercultural, privilegia significados propios de la 
ciencia moderna para algunos estudiantes, como para otros lo puede hacer desde sus propias formas de conocimiento (Uribe, 2019).

En relación con esto, una visión hegemónica no es posible en una sociedad diversa. Es necesario el cuestionamiento de la relación ciencia-escuela occidental hegemónica y que se estudien los aspectos que limitan la generación de ambientes y dinámicas interculturales; la educación en ciencias se debe construir desde el diálogo entre múltiples bases culturales (Uribe, 2019). Walsh (2004) sugiere que el enfoque intercultural en la enseñanza de las ciencias y en la formación de profesores de ciencias contribuye a reconstruir la lógica de cómo los diversos grupos étnicos y culturales han producido conocimiento en las ciencias de la naturaleza bajo una mirada de interculturalidad.

\section{Dimensión de diversidad epistémica}

Es definida como la valoración de los conocimientos de acuerdo con su funcionalidad en las diversas culturas. La diversidad cultural en la enseñanza de las ciencias y en la formación de profesores de ciencias contribuye a reconstruir la lógica de como los diversos grupos étnicos y culturales han producido conocimiento en las ciencias de la naturaleza bajo una mirada de interculturalidad epistémica (Walsh, 2004).

Por esto, desde la enseñanza de las ciencias es imperativo considerar que en la escuela existen diferentes epistemologías con sus respectivos discursos, por lo que se pueden valorar diferentes tipos de conocimiento (Essobra, 2006). De esta forma, la diversidad cultural da especial importancia a los contenidos y costumbres culturales que, para la educación contemporánea, invitan a reflexionar desde el aula por una puesta panorámica multicultural y de intercambio cultural (Bhabha, 2002). 
La diversidad epistémica reconoce la heterogeneidad del pensamiento, lo cual porsibilita que una persona pueda albergar numerosos modos de conocer y pensar. En este sentido, podría definirse como la valoración de los conocimientos según su funcionalidad en las diversas culturas (Mortimer y El Hani, 2014; Rodríguez y Molina, 2012; Valderrama, 2016).

\section{Dimensión política-escolar}

Es definida como la relación presente entre la educación propia (contexto cultural), nacional e internacional (occidental), a partir de las diferentes normativas de nuestro territorio y las tendencias globales. Martínez (2017) manifiesta que, en gran cantidad de situaciones, las políticas educativas y currículares (especialmente las latinoamericanas) intentan proyectar una identidad profesional docente sometida a un perfil técnico, en donde el profesor es visto como implementador de orientaciones establecidas para otros lugares y contextos, por otras contingencias, lo que conduce la docencia de una dimensión de saber y de práctica política.

Tales políticas, principalmente las vinculadas a la enseñanza de ciencias, no consideran la especificidad de entendimiento pedagógico e intentan sustituir la educación solo por la enseñanza, y la enseñanza exclusivamente de las temáticas de contenido, derivadas exclusivamente de la lógica científica. En este proceso, la educación en ciencias está restringida al proceso de transmitir información científica. Lopes (2008) argumenta que la investigación de políticas de currículo se puede beneficiar con aportes teórico-metodológicos que permitan considerar dimensiones contextuales, articulaciones entre demandas de sujetos colectivos diversos y reinterpretaciones discursivas. De esta manera, se aporta a la construcción de consensos que pueden desenredar posibles conflictos tras la lucha por nuevas hegemonías del conocimiento. 


\section{Dimensión educativa}

Está definida a través de las relaciones entre cognición, enseñanza y aprendizaje de las ciencias desde la educación tradicional (propia), nacional y occidental. Gurgel (2003) analiza que el énfasis sociocultural se puede constituir en un camino posible para avanzar en la construcción de un currículo orientado por aspectos sociológicos, políticos y epistemológicos, y así ampliar las dimensiones de su análisis frente al momento actual, en el cual la globalización tecnoeconómica parece estar aniquilando las posibilidades de sobrevivencia de procesos sociales diversos.

Asimismo, la autora anota que también los profesores tienen dificultades para tener en cuenta los elementos del contexto del conocimiento y de la complejidad de la realidad social de las escuelas y de su aprendizaje. Esta perspectiva adopta la idea de la diversidad cultural del aula; por lo tanto, el currículo se considera como un espacio de construcción de las culturas. Para Geelan (1997) y El-Hani y Bizzo (1999), el conocimiento científico no puede ser visto en la escuela como algo dado, sino que este debe ser aprendido; dan importancia al papel de la cultura en el desarrollo y en la validación de las creencias individuales, y buscan insertar la ciencia en el contexto sociocultural, con lo que la consideran una segunda cultura para los estudiantes. Finalmente, con respecto a las investigaciones en la enseñanza de las ciencias de la naturaleza y su relación con la cultura, cada vez más se preocupa por estudiar las relaciones entre enseñanza, aprendizaje y cultura. $\mathrm{Al}$ respecto, son varios los campos de trabajo que han emergido (Molina et ál., 2014).

La revisión de estas dimensiones se evidencia en el instrumento 1 (tabla 2). 
Tabla 2. Instrumento n. ${ }^{\circ}$ 1. Entrevista con base en situaciones contextuales

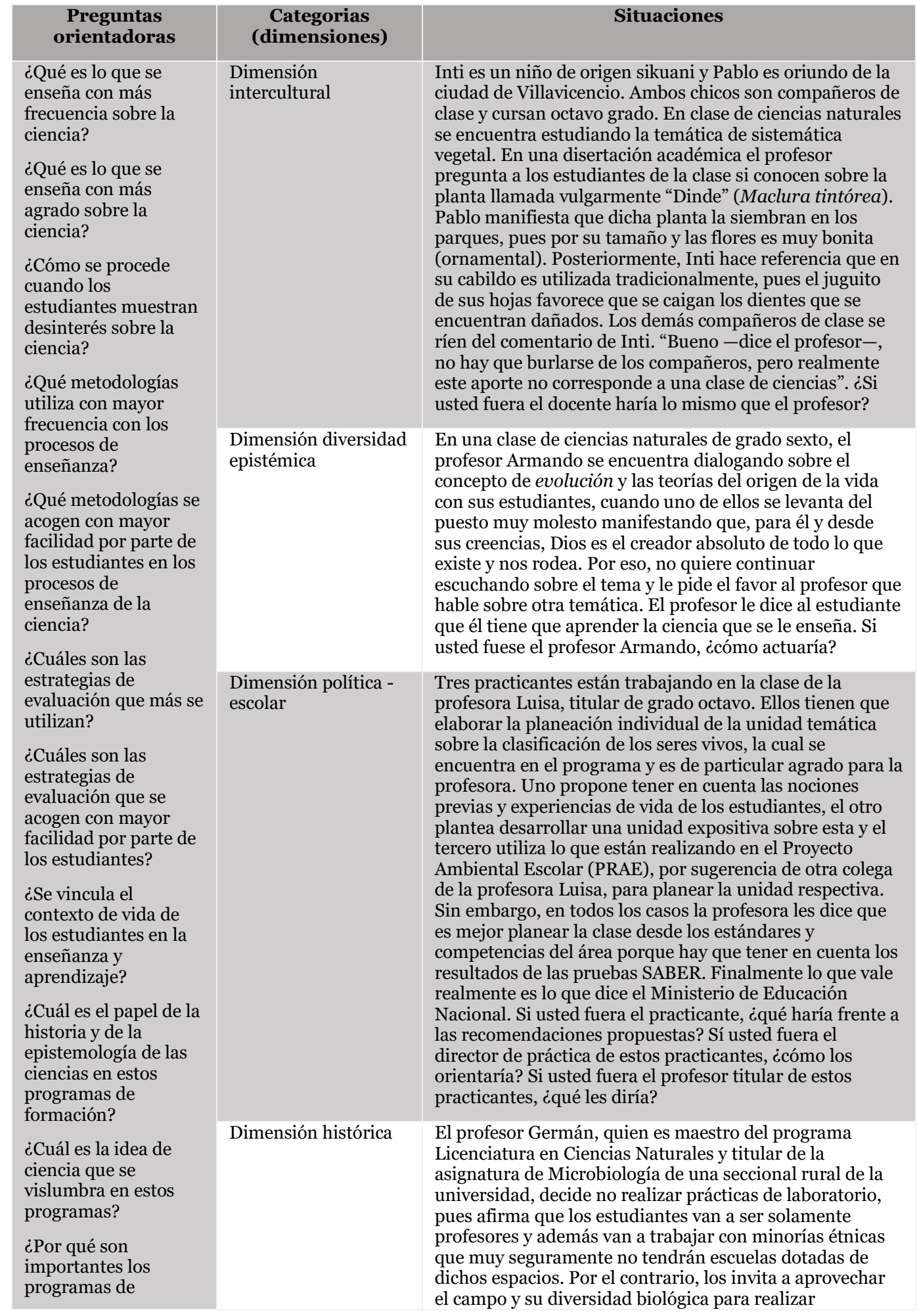

\section{Análisis}

ISSN: 0120-8454 | e-ISSN: 2145-9169 | DOI: https://doi.org/10.15332/21459169

Vol. 53 N.0 98 | enero-junio de 2021 


\begin{tabular}{|c|c|c|}
\hline $\begin{array}{l}\text { Preguntas } \\
\text { orientadoras }\end{array}$ & $\begin{array}{c}\text { Categorias } \\
\text { (dimensiones) }\end{array}$ & Situaciones \\
\hline \multirow[t]{2}{*}{$\begin{array}{l}\text { formación de } \\
\text { profesores de } \\
\text { ciencias? } \\
\text { ¿Qué importancia } \\
\text { tiene el entorno para } \\
\text { los programas de } \\
\text { formación? }\end{array}$} & & $\begin{array}{l}\text { actividades más acordes a la población de su contexto. La } \\
\text { directora del programa se enteró de que el profesor no } \\
\text { enseñaba nada y el programa estaba atrasado, entonces lo } \\
\text { llama a pedirle cuentas sobre su actuación. ¿Usted, como } \\
\text { docente, qué opina sobre estas dos formas de enfrentar la } \\
\text { docencia? ¿Usted considera que el espacio físico del } \\
\text { laboratorio es fundamental en el proceso de enseñanza de } \\
\text { las ciencias naturales? }\end{array}$ \\
\hline & Dimensión educativa & $\begin{array}{l}\text { Camila, estudiante de } 10 .^{\circ} \text { semestre de una licenciatura } \\
\text { en Biología, asiste a la conferencia de un profesor de } \\
\text { básica secundaria del sector oficial, quien inicia su } \\
\text { intervención diciendo: “... cuando era niño fue dañino con } \\
\text { su tierra, se la pasaba tumbando madera del bosque. Por } \\
\text { eso, cuando entendió el deber que cada uno tiene de } \\
\text { cuidar el planeta, inclina sus esfuerzos a desarrollar en la } \\
\text { comunidad escolar la conservación por el medio } \\
\text { ambiente. Estudió Licenciatura en Química, se dedicó a la } \\
\text { enseñanza de las ciencias naturales y lleva más de } 15 \text { años } \\
\text { en la docencia. En el último colegio, el profesor trabaja } \\
\text { como coordinador de convivencia y, con un solo grupo de } \\
\text { estudiantes de grado noveno, desarrolla actividades de } \\
\text { recuperación del entorno de la escuela, aplicando el } \\
\text { conocimiento científico que posee. Camila comenta con su } \\
\text { compañera Lina, que es una situación ideal pero utópica, } \\
\text { ya que en clase lo objetivo son los contenidos sobre el } \\
\text { medio ambiente y no las actitudes que tengan los } \\
\text { estudiantes frente a él. Lina está de acuerdo y además } \\
\text { agrega que un trabajo como el del profesor es fácil cuando } \\
\text { se tiene solo un grupo de alumnos, pues esto no sería } \\
\text { posible con la carga académica que tiene un docente } \\
\text { normal (por lo menos } 6 \text { grupos), sin contar con todos los } \\
\text { formatos que hay que elaborar. ¿Cuál ha sido su } \\
\text { experiencia al respecto? ¿Por qué cree que se presentan } \\
\text { estas posturas? }\end{array}$ \\
\hline
\end{tabular}

Fuente: elaboración propia.

Con el fin de analizar las concepciones docentes presentes en los documentos maestros de los programas de lincenciatura estudiados, se les aplicó un cuestionario ReCo (tabla 3). Corresponde a un instrumento que, a partir de la formulación de preguntas orientadoras, buscó entrevistar a los documentos maestros de los tres programas de formación inicial de profesores de Ciencias Naturales y Educación Ambiental de esta investigación.

Los instrumentos ReCo sobre representaciones de contenido, propuestos por Loughran et ál. (2004) como CoRe (Content Representation), han sido muy utilizados para conocer el conocimiento pedagógico del contenido de profesores (pedagogical content knowledge [PCK]). Ha buscado desde sus 
finalidades responder preguntas o cuestionamientos sobre el "conocimiento del maestro" a través de la reflexión sobre sus epistemologías, ideas o concepciones, a partir de ellas mismas, como agentes de interrelación a sus prácticas educativas (Martinez y Valbuena, 2013).

De otra parte, los documentos maestros sustentan los registros calificados, la oferta y desarrollo de programas académicos de educación superior en nuestro país. Estos se rigen bajo lo consagrado por el Ministerio de Educación Nacional (MEN) a través del Decreto 1330 de 2019. Se analizaron las concepciones docentes bajo los siguientes puntos: denominación del programa, justificación del programa, aspectos curriculares, organización de las actividades académicas y proceso formativo, investigación, innovación y creación artística y cultural, relación con el sector externo y profesores.

Tabla 3. Cuestionario ReCo (Representaciones de Contenido)

\begin{tabular}{|c|c|c|c|c|}
\hline $\begin{array}{l}\text { Dimensión } \\
\text { histórica }\end{array}$ & $\begin{array}{l}\text { Dimensión } \\
\text { intercultural }\end{array}$ & $\begin{array}{l}\text { Dimensión } \\
\text { diversidad } \\
\text { epistémica }\end{array}$ & $\begin{array}{c}\text { Dimensión } \\
\text { política- } \\
\text { escolar }\end{array}$ & $\begin{array}{l}\text { Dimensión } \\
\text { educativa }\end{array}$ \\
\hline $\begin{array}{l}\text { ¿En el texto se } \\
\text { proyecta el } \\
\text { conocimiento } \\
\text { científico como una } \\
\text { construcción } \\
\text { permanente y } \\
\text { provisional en } \\
\text { relación con aspectos } \\
\text { propios de la realidad } \\
\text { natural y social? Ello } \\
\text { implica que las } \\
\text { teorías científicas que } \\
\text { se desarrollan } \\
\text { producto del progreso } \\
\text { en la investigación } \\
\text { científica son siempre } \\
\text { provisionales y, por } \\
\text { tanto, no constituyen } \\
\text { en sí mismas la } \\
\text { realidad? }\end{array}$ & $\begin{array}{l}\text { ¿En el texto se } \\
\text { proyecta a la } \\
\text { ciencia como una } \\
\text { construcción } \\
\text { dialógica entre } \\
\text { culturas? }\end{array}$ & $\begin{array}{l}\text { ¿En el texto se } \\
\text { resalta la } \\
\text { valoración de } \\
\text { los } \\
\text { conocimientos } \\
\text { científicos y } \\
\text { tradicionales } \\
\text { según la } \\
\text { funcionalidad } \\
\text { de las diversas } \\
\text { culturas? }\end{array}$ & $\begin{array}{l}\text { ¿La enseñanza } \\
\text { de las ciencias } \\
\text { debe obedecer } \\
\text { a la política } \\
\text { pública } \\
\text { educativa } \\
\text { (estándares, } \\
\text { competencias y } \\
\text { contenidos } \\
\text { disciplinares)? }\end{array}$ & $\begin{array}{l}\text { ¿En el texto, } \\
\text { el proceso de } \\
\text { la enseñanza } \\
\text { de las ciencias } \\
\text { es visto como } \\
\text { una conexión } \\
\text { entre los } \\
\text { conocimientos } \\
\text { ancestrales y } \\
\text { científicos? }\end{array}$ \\
\hline
\end{tabular}




\begin{tabular}{|c|c|c|c|c|}
\hline $\begin{array}{l}\text { Dimensión } \\
\text { histórica }\end{array}$ & $\begin{array}{l}\text { Dimensión } \\
\text { intercultural }\end{array}$ & $\begin{array}{l}\text { Dimensión } \\
\text { diversidad } \\
\text { epistémica }\end{array}$ & $\begin{array}{c}\text { Dimensión } \\
\text { política- } \\
\text { escolar }\end{array}$ & $\begin{array}{l}\text { Dimensión } \\
\text { educativa }\end{array}$ \\
\hline $\begin{array}{l}\text { ¿La investigación } \\
\text { científica se considera } \\
\text { adecuada cuando, } \\
\text { producto de las } \\
\text { revisiones necesarias } \\
\text { (contrarias a } \\
\text { ordenamientos } \\
\text { teleológicos), se va } \\
\text { encontrando } \\
\text { coherencia entre la } \\
\text { concepción teórica } \\
\text { que fundamenta la } \\
\text { situación } \\
\text { problemática y las } \\
\text { expectativas } \\
\text { esperadas en los } \\
\text { resultados de dicha } \\
\text { investigación? }\end{array}$ & $\begin{array}{l}\text { ¿En el texto se } \\
\text { plantea una } \\
\text { formación del } \\
\text { profesorado para } \\
\text { una enseñanza } \\
\text { de la ciencia } \\
\text { desde contextos } \\
\text { culturalmente } \\
\text { diferenciados? }\end{array}$ & $\begin{array}{l}\text { ¿Lo práctico y } \\
\text { sistematizable } \\
\text { del } \\
\text { conocimiento } \\
\text { tradicional es } \\
\text { funcionable y } \\
\text { creíble? }\end{array}$ & $\begin{array}{l}\text { ¿En el } \\
\text { documento se } \\
\text { puede } \\
\text { evidenciar si se } \\
\text { priorizan los } \\
\text { conocimientos } \\
\text { propios frente } \\
\text { a los } \\
\text { nacionales o } \\
\text { los globales? }\end{array}$ & $\begin{array}{l}\text { ¿En el texto se } \\
\text { puede } \\
\text { evidenciar } \\
\text { que el } \\
\text { aprendizaje } \\
\text { de las ciencias } \\
\text { naturales y la } \\
\text { educación } \\
\text { ambiental } \\
\text { puede estar } \\
\text { delimitado } \\
\text { desde el } \\
\text { contexto } \\
\text { cultural? }\end{array}$ \\
\hline $\begin{array}{l}\text { ¿En el documento se } \\
\text { evidencia que el } \\
\text { conocimiento } \\
\text { científico surge por el } \\
\text { interés de solucionar } \\
\text { por parte de las } \\
\text { comunidades } \\
\text { científicas (que son } \\
\text { sub-culturas } \\
\text { académicas), } \\
\text { situaciones } \\
\text { problemáticas de } \\
\text { interés? ¿Las } \\
\text { respuestas } \\
\text { (conceptuales o } \\
\text { prácticas) a dichas } \\
\text { situaciones, son en } \\
\text { muchas ocasiones } \\
\text { una alternativa para } \\
\text { dar respuestas a } \\
\text { necesidades sentidas } \\
\text { por las sociedades en } \\
\text { general (cultura)? }\end{array}$ & $\begin{array}{l}\text { ¿Ante la } \\
\text { diversidad } \\
\text { cultural presente } \\
\text { en la escuela, se } \\
\text { deben enseñar } \\
\text { los conceptos de } \\
\text { ciencia más } \\
\text { generalizados? }\end{array}$ & $\begin{array}{l}\text { ¿Se acepta } \\
\text { como fuentes de } \\
\text { conocimiento } \\
\text { escolar las } \\
\text { experiencias y } \\
\text { conocimientos } \\
\text { ancestrales u } \\
\text { otros tipos } \\
\text { diferentes a los } \\
\text { conocimientos } \\
\text { científicos } \\
\text { convencionales? }\end{array}$ & $\begin{array}{l}\text { ¿En el } \\
\text { documento se } \\
\text { vislumbra al } \\
\text { profesor de } \\
\text { ciencias } \\
\text { naturales y } \\
\text { educación } \\
\text { ambiental } \\
\text { como eje } \\
\text { fundamental } \\
\text { de la } \\
\text { transformación } \\
\text { social y } \\
\text { apropiación } \\
\text { del territorio? }\end{array}$ & $\begin{array}{l}\text { ¿La cognición } \\
\text { sobre la } \\
\text { ciencia es } \\
\text { innata y } \\
\text { derivada del } \\
\text { contexto } \\
\text { cultural? }\end{array}$ \\
\hline $\begin{array}{l}\text { ¿En el texto se explica } \\
\text { el contexto histórico } \\
\text { que enmarca el } \\
\text { desarrollo de las } \\
\text { ciencias? }\end{array}$ & $\begin{array}{l}\text { ¿En el texto se } \\
\text { evidencia una } \\
\text { proyección de la } \\
\text { formación del } \\
\text { profesorado en } \\
\text { ciencias, que } \\
\text { promueva el } \\
\text { dialogo entre } \\
\text { culturas } \\
\text { presentes desde } \\
\text { la diversidad en }\end{array}$ & $\begin{array}{l}\text { ¿La validez de } \\
\text { los } \\
\text { conocimientos } \\
\text { científicos o de } \\
\text { los } \\
\text { conocimientos } \\
\text { tradicionales } \\
\text { son subjetivos } \\
\text { al contexto en } \\
\text { donde se } \\
\text { desarrolla? }\end{array}$ & $\begin{array}{l}\text { ¿En los } \\
\text { documentos se } \\
\text { alude la } \\
\text { importancia de } \\
\text { homogeneizar } \\
\text { el } \\
\text { conocimiento } \\
\text { científico para } \\
\text { superar las } \\
\text { desigualdades } \\
\text { educativas? }\end{array}$ & $\begin{array}{l}\text { ¿En el texto se } \\
\text { evidencia que, } \\
\text { para enseñar } \\
\text { ciencias } \\
\text { naturales y } \\
\text { educación } \\
\text { ambiental en } \\
\text { contextos } \\
\text { culturales } \\
\text { diversos, es } \\
\text { necesario } \\
\text { desarrollar }\end{array}$ \\
\hline
\end{tabular}

\section{Análisis}

ISSN: 0120-8454 | e-ISSN: 2145-9169 | DOI: https://doi.org/10.15332/21459169

Vol. 53 N.o 98 | enero-junio de 2021 


\begin{tabular}{|c|c|c|c|c|}
\hline $\begin{array}{l}\text { Dimensión } \\
\text { histórica }\end{array}$ & $\begin{array}{l}\text { Dimensión } \\
\text { intercultural }\end{array}$ & $\begin{array}{l}\text { Dimensión } \\
\text { diversidad } \\
\text { epistémica }\end{array}$ & $\begin{array}{c}\text { Dimensión } \\
\text { política- } \\
\text { escolar }\end{array}$ & $\begin{array}{l}\text { Dimensión } \\
\text { educativa }\end{array}$ \\
\hline & $\begin{array}{l}\text { el aula de clases } \\
\text { y la escuela? }\end{array}$ & & & $\begin{array}{l}\text { una didáctica } \\
\text { y una } \\
\text { pedagogía } \\
\text { específica } \\
\text { para tal fin? }\end{array}$ \\
\hline $\begin{array}{l}\text { ¿Una nueva teoría } \\
\text { científica ha de ser } \\
\text { más coherente, } \\
\text { predictiva y } \\
\text { explicativa, } \\
\text { caracterizándose } \\
\text { entonces por } \\
\text { solucionar un tanto } \\
\text { mejor aquellos } \\
\text { problemas de su } \\
\text { interés?, Ello implica } \\
\text { que la nueva teoría } \\
\text { casi siempre implica } \\
\text { rupturas respecto a } \\
\text { teorías anteriores. }\end{array}$ & $\begin{array}{l}\text { ¿En el texto se } \\
\text { hace referencia a } \\
\text { la ciencia desde } \\
\text { la } \\
\text { heterogeneidad } \\
\text { regional? }\end{array}$ & $\begin{array}{l}\text { ¿Solo el tipo de } \\
\text { conocimiento } \\
\text { que puede ser } \\
\text { sistematizable, } \\
\text { medible, } \\
\text { cuantificable, } \\
\text { replicable, } \\
\text { puede explicar } \\
\text { fenómenos } \\
\text { naturales? }\end{array}$ & $\begin{array}{l}\text { ¿En el texto se } \\
\text { asocia la } \\
\text { ciencia desde } \\
\text { la diversidad } \\
\text { cultural con } \\
\text { respeto a la } \\
\text { discriminación } \\
\text { social, } \\
\text { económica o de } \\
\text { género? }\end{array}$ & $\begin{array}{l}\text { ¿Se evidencia } \\
\text { en el } \\
\text { documento } \\
\text { del programa } \\
\text { académico la } \\
\text { importancia y } \\
\text { relación de los } \\
\text { conocimientos } \\
\text { científicos y } \\
\text { tradicionales } \\
\text { como base } \\
\text { para el } \\
\text { desarrollo } \\
\text { científico y } \\
\text { tecnológico de } \\
\text { la región? }\end{array}$ \\
\hline
\end{tabular}

Fuente: elaboración propia.

\section{Resultados}

A las universidades del Valle (sedes Cali y Buenaventura), Córdoba (sede Montería) y Pedagógica y Tecnológica de Colombia (sede Tunja) denominadas como caso 1, caso 2 y caso 3 respectivamente, se les aplicaron dos instrumentos de intervención, con el fin de recabar e interpretar información a partir de entrevistas a docentes y documentos maestros de los programas de ciencias naturales y educación ambiental, por medio de situaciones en contexto y cuestionario sobre representaciones de contenido (ReCo). Se indagaron sus concepciones acerca de la ciencia vista desde la perspectiva de diversidad cultural. La información obtenida fue triangulada a partir de tablas de coocurrencia y redes semánticas producto del software ATLAS.ti. V8 (tabla 4).

Para la Universidad del Valle (caso 1), se encontró una disrupción entre las concepciones docentes presentes, pues el documento maestro desde la 
generalidad enmarca una postura universal de la ciencia (figura 3), mientras la tendencia global de las entrevistas docentes (sedes Cali y Buenaventura) apunta a la interculturalidad:

Yo creo que la clave es un ejercicio, la práctica pedagógica es fundamento dialógico entre los diferentes mundos que se ponen en juego y ahí es donde está la capacidad como profesional de hacer un ejercicio, en donde vuelvo y acuño esa es la idea, ser capaz de poner en diálogo diferentes realidades. [DUVSP, (28)]

En relación con lo mencionado por el docente, la interculturalidad debe ser entendida como un diálogo de saberes que promueve la descolonización del conocimiento. De esta manera, la formación de profesores en Colombia debe hacer provecho de la riqueza étnocultural, lingüística, biológica y geográfica, como una prerrogativa para construir conocimiento desde la heterogeneidad de culturas (Uribe, 2019).

De otra parte, la Universidad de Córdoba (caso 2) presenta puntos de congruencia y otros polarizados entre las concepciones de ciencia vistas desde la diversidad cultural, en donde el documento maestro y la entrevista docente se ciñen en términos generales al universalismo, haciendo salvedad a la dimensión histórica y la intercultural que perfilan al contextualismo cultural e interculturalidad. 
Tabla 4. Concepciones, docente U. Valle sede regional Buenaventura.

Coocurrencias de unidades de contenido entre tendencias de progresión y familias (situaciones en contexto) ATLAS.ti.

\begin{tabular}{|c|c|c|c|c|c|}
\hline & $\begin{array}{c}\text { Contextualista } \\
9\end{array}$ & $\begin{array}{l}\text { Interculturalista } \\
12\end{array}$ & $\begin{array}{c}\text { Multiculturalista } \\
1\end{array}$ & $\begin{array}{l}\text { Pluralista Epistémico } \\
0\end{array}$ & $\begin{array}{c}\text { Universalista } \\
14\end{array}$ \\
\hline D. Epistémica 7 & & & $1(0,14)$ & & $1(0,05)$ \\
\hline D. Educativa & $7(0,37)$ & $6(0,26)$ & & & $5(0,19)$ \\
\hline D. Histórica & & $1(0,06)$ & & & $1(0,05)$ \\
\hline D. Intercultural 14 & $4(0,21)$ & $8(0,44)$ & & & \\
\hline D. Político - Escolar 21 & $5(0,20)$ & $9(0,38)$ & $1(0,05)$ & & $2(0,06)$ \\
\hline Códigos entrecruzados & & & & $\begin{array}{l}\text { idada } 1 \text { demuestramayor correlacio } \\
\text { hipótesis de progresión y familias } \\
\text { (categorias sistemáticas). }\end{array}$ & \\
\hline
\end{tabular}

Fuente: elaboración propia.

\section{Análisis}

ISSN: 0120-8454 | e-ISSN: 2145-9169 | DOI: https://doi.org/10.15332/21459169

Vol. 53 N.0 98 | enero-junio de 2021 
Figura 3. Concepciones docentes, documento maestro U. Valle. Cuestionario ReCo. Ejemplo de red semántica de unidades de contenido entre hipótesis de progresión y familias ATLAS.ti.

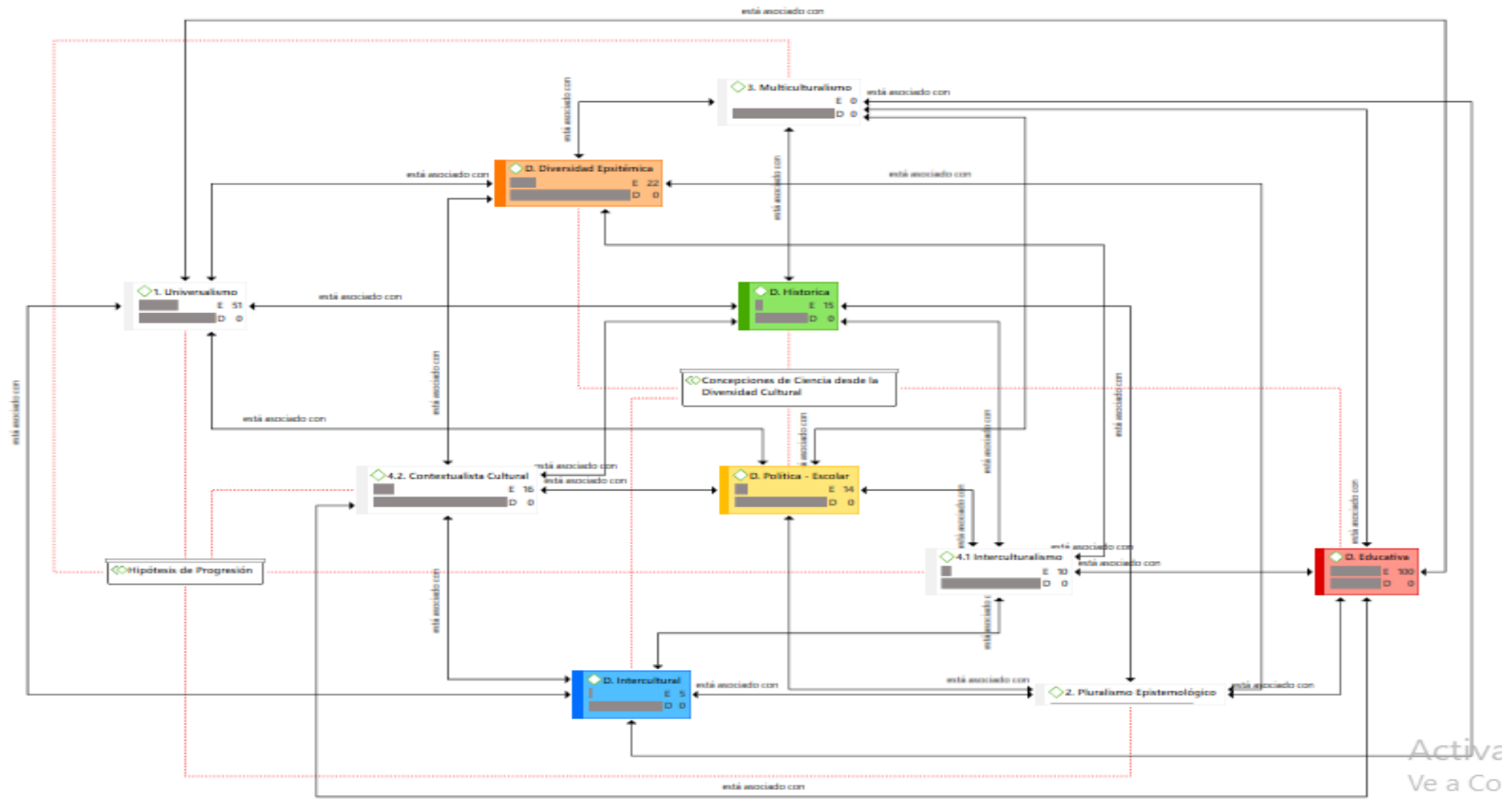

Fuente: elaboración propia.

\section{Análisis}

ISSN: 0120-8454 | e-ISSN: 2145-9169 | DOI: https://doi.org/10.15332/21459169

Vol. 53 N.o 98 | enero-junio de 2021 
[...] Por esa razón, el problema de la enseñanza solo se puede entender como un problema del conocimiento. Tal conocimiento está dado por la ciencia que el maestro enseña, los conceptos que los estudiantes tienen, antes de ser formalmente enseñados y la interrelación entre los conceptos de las diversas ciencias que el maestro enseña. [DMUV, (49)]

En la enseñanza de la ciencias, parece aún prevalecer entre docentes e investigadores una diferenciación entre los conocimientos científicos y las concepciones denominadas erróneas, en donde se sobrevalora el conocimiento producto de la ciencia frente a otras diversas formas de conocimiento. Dicha situación incluso lleva al desconocimiento de estas en la enseñanza (Pérez, 2014). 
Tabla 5. Concepciones, Docente U. Córdoba sede Montería. Coocurrencias de unidades de contenido entre hipótesis de progresión y familias (situaciones en contexto)

\begin{tabular}{|c|c|c|c|c|c|c|}
\hline & & Contextualista3o & $\begin{array}{l}\text { Interculturalista } \\
\qquad 5\end{array}$ & $\begin{array}{c}\text { Multiculturalista } \\
\mathbf{3}\end{array}$ & $\begin{array}{l}\text { Pluralista epistémico } \\
10\end{array}$ & $\begin{array}{c}\text { Universalista } \\
\mathbf{3}\end{array}$ \\
\hline D. Epistémica & 3 & & $4(0,40)$ & $1(0,09)$ & $1(0,06)$ & \\
\hline D. Educativa & 48 & $27(0,53)$ & $2(0,04)$ & $2(0,04)$ & $8(0,16)$ & $3(0,06)$ \\
\hline D. Histórica & 22 & $15(0,41)$ & & & $2(0,07)$ & $2(0,09)$ \\
\hline D. Intercultural & 7 & & & & $6(0,55)$ & \\
\hline D. Político Escolar & 22 & $16(0,44)$ & & $1(0,04)$ & $6(0,10)$ & $2(0,09)$ \\
\hline
\end{tabular}

Fuente: elaboración propia. 
En relación con la Universidad Pedagógica y Tecnológica de Colombia (caso 3), se aprecian matices de concordancia y puntos disímiles presentes en las concepciones docentes que se asocian al documento institucional y las situaciones en contexto presentes en la entrevista. Sin embargo, en términos generales, sobresale un posicionamiento que tiende al universalismo de la ciencia. No obstante, hace salvedad en ciertos matices presentes en el escrito maestro que tiende desde el dominio intercultural al contextualismo cultural.

Los profesores que estamos transformando a otros tenemos un modelo hegemónico en el que nos formamos y es muy difícil romperlo a mí me paso algo muy curioso cuando quise hacer el árbol de problemas con mis profesores y habían unos filósofos que decían: "Profesora todo no es causa - efecto" un momentico considérenme a mi yo tengo ese modelo porque así es que yo cuestiono y llego a la implementación y claro profesores usted complemente el modelo pero tengo que reconocer que ese es mi modelo o sea el hecho de que ahorita estemos descolonizando no quiere decir que no reconozca que yo soy más eurocéntrica que más no podemos ser. [DUPTC, (59)]

Desde diferentes rasgos históricos y políticos en el marco del desarrollo educativo, el universalismo se ha caracterizado por la reducción de las diferencias en la búsqueda de una identidad particular, tal vez la denominada "cultura científica". En este sentido, dicha cultura podría definirse como la expresión del pensamiento científico, que sustenta su actuación en la búsqueda de solución de problemas y fenómenos de la naturaleza que atañan a la sociedad actual, a través del uso de un método que permite indagar y explicar dichas situaciones por medio de procesos validables (Gutiérrez et ál., 2018). Esto favorece su superposición sobre 
otros tipos de conocimientos considerados poco confiables o alternos, con lo cual se legitiman actos epistemicidas y coloniales del saber (Walsh, 2004; Molina et ál., 2014; Uribe, 2019).

Finalmente, se realizó una compilación por clústeres de las tablas de coocurrencia presentes en los diversos casos relacionados a las situaciones en contexto y los cuestionarios ReCo (tabla 6), los cuales se interpretaron y analizaron. Para Colombia se encontró una concepción docente que, desde la diversidad cultural, a grandes rasgos, aprecia la ciencia de forma universal como eje fundamental del proceso formativo de los futuros licenciados en ciencias naturales y educación ambiental. Sin embargo, reconocen la importancia de la interacción y dialogismo entre conocimientos propios y científicos en procesos de enseñanza y aprendizaje de las ciencias naturales y la educación ambiental. Atendiendo el enorme acervo cultural que destaca nuestra nación y reflexionando sobre esta consideración, la formación docente debe emanciparse como alternativa y respuesta educativa que permita acercar al estudiantado a un conocimiento que representa a una sociedad plural (Guido et ál., 2013). Entonces, es imperativo desde la educación científica romper con la imagen de la ciencia como saber universal y aproximar conocimientos alternos y legítimos de nuestras comunidades a los procesos formativos en nuestras aulas de clasesAsimismo, es necesario reivindicar la imagen histórica y social que ha plasmado el conocimiento científico como agente epistemicida y perpetrador de exclusiones culturales, racistas, de género y saberes.

Perspectivas como la epistemología del sur (De Sousa Santos, 2009) permiten reflexionar sobre la reivindicación de los saberes propios de 
nuestra nación frente aquellos conocimientos universales agentes del progreso y de la modernidad, que desde la occidentalización del mundo no son nada menos que instrumentos de homogenización de la sociedad. En relación con lo expuesto, surgen como propuestas la descolonización del conocimiento dentro de la formación docente (Walsh, 2004), con lo que se permita reconocer la diversidad cultural como una riqueza que potencia el acto educativo dentro de los procesos de enseñanza y aprendizaje de las ciencias naturales. A partir de ello, se favorece la conservación de nuestro acervo y se establecen rutas que conduzcan a un diálogo intercultural en la escuela, por medio de una apertura de las concepciones de los sujetos a través de la comprensión e interacción de pluralidades epistémicas.

Tabla 6. Resúmenes de cuadros de coocurrencia. Caso Colombia

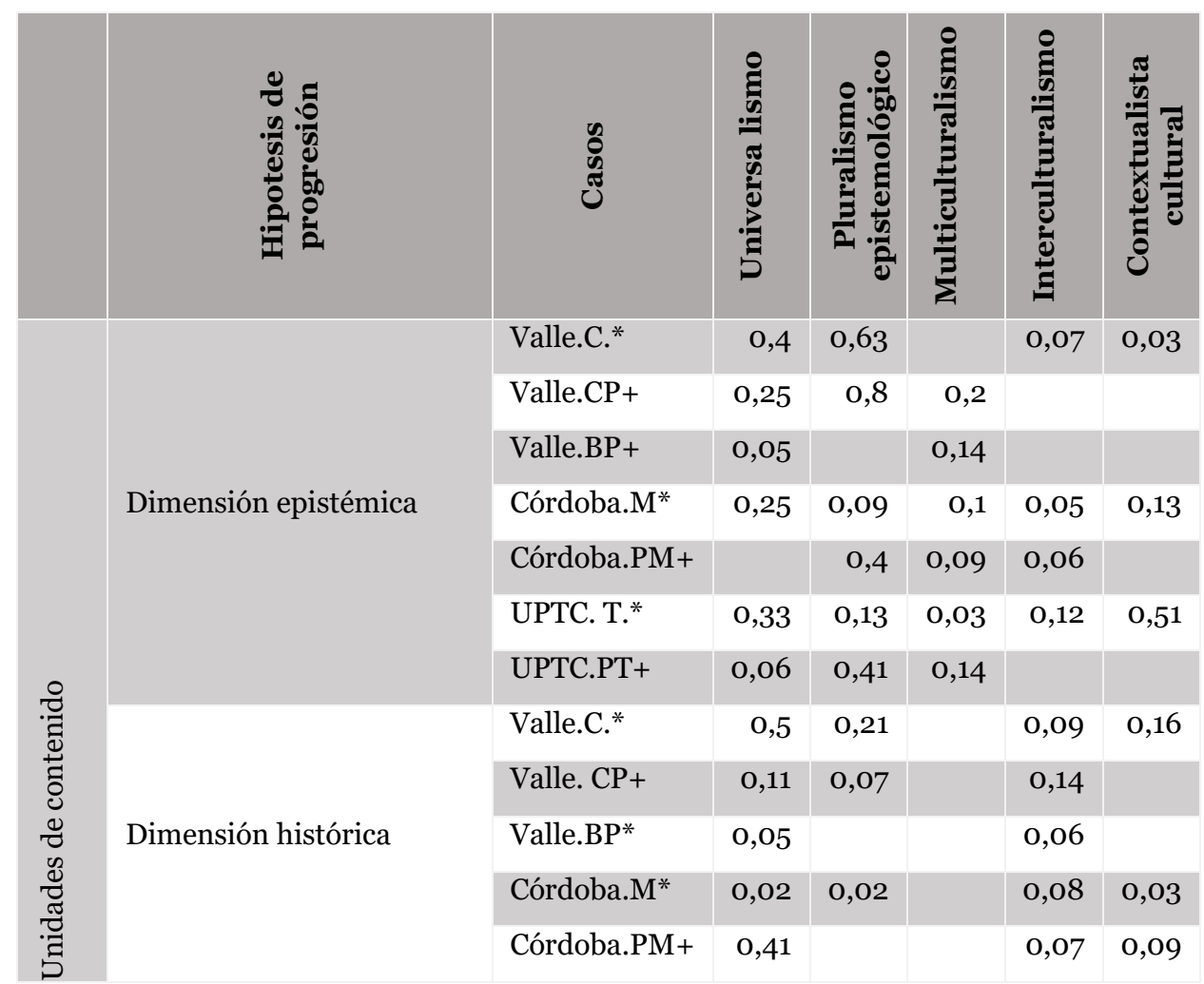

Análisis

ISSN: 0120-8454 | e-ISSN: 2145-9169 | DOI: https://doi.org/10.15332/21459169

Vol. 53 N.o 98 | enero-junio de 2021 


\begin{tabular}{|c|c|c|c|c|c|c|}
\hline 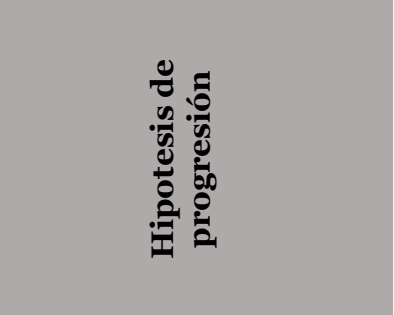 & $\begin{array}{l}\text { है } \\
\text { है } \\
\text { Uే }\end{array}$ & 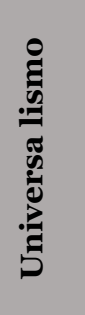 & 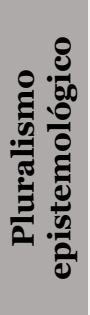 & 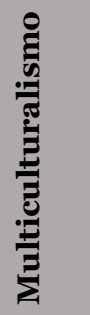 & 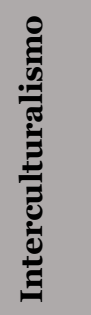 & 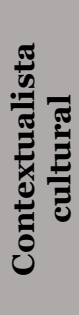 \\
\hline & UPTC. T.* & 0,26 & 0,04 & & 0,04 & 0,03 \\
\hline & UPTC.PT+ & 0,28 & 0,14 & 0,08 & 0,13 & 0,03 \\
\hline \multirow{7}{*}{ Dimensión educativa } & Valle.C. * & 0,16 & & & 0,04 & 0,11 \\
\hline & Valle. CP+ & 0,41 & 0,14 & 0,04 & 0,29 & 0,15 \\
\hline & Valle.BP+ & 0,19 & & & 0,26 & 0,37 \\
\hline & Córdoba.M* & 0,46 & & 0,03 & 0,11 & 0,31 \\
\hline & Córdoba.PM+ & 0,53 & 0,04 & 0,04 & 0,16 & 0,06 \\
\hline & UPTC. T.* & 0,35 & 0,11 & 0,01 & 0,14 & 0,46 \\
\hline & UPTC.PT+ & 0,43 & 0,16 & 0,04 & 0,17 & 0,1 \\
\hline \multirow{7}{*}{ Dimensión intercultural } & Valle.C.* & & 0,04 & & 0,36 & 0,11 \\
\hline & Valle. CP+ & & & & 0,68 & 0,42 \\
\hline & Valle.BP+ & & & & 0,44 & 0,21 \\
\hline & Córdoba.M* & 0,02 & & & 0,29 & 0,05 \\
\hline & Córdoba.PM+ & & & & 0,55 & \\
\hline & UPTC. T.* & & 0,07 & 0,17 & 0,13 & 0,02 \\
\hline & UPTC.PT+ & & & & 0,57 & 0,19 \\
\hline \multirow{3}{*}{ Dimensión política escolar } & Valle. $C^{*}$ & 0,18 & & & 0,09 & 0,07 \\
\hline & Valle. CP+ & 0,17 & & 0,09 & 0,14 & \\
\hline & Valle.BP+ & 0,06 & & 0,05 & 0,38 & 0,2 \\
\hline
\end{tabular}

Fuente: elaboración propia.

\section{Conclusiones}

Interpretando los discursos narrativos implícitos en los documentos maestros de los programas de formación de licenciaturas en ciencias naturales y educación ambiental, y las transcripciones de las entrevistas realizadas a los docentes de las Universidades del Valle, Córdoba, y

Análisis

ISSN: 0120-8454 | e-ISSN: 2145-9169 | DOI: https://doi.org/10.15332/21459169

Vol. 53 N.o 98 | enero-junio de 2021 
Pedagógica y Tecnológica de Colombia, se proyecta desde el marco general una postura universal de la ciencia como eje fundamental del proceso formativo de los futuros licenciados, en relación con la concordancia encontrada en los dos instrumentos de intervención aplicados a partir de la mayoría de las familias analizadas (dimensión educativa, dimensión histórica, dimensión política-escolar e incluso dimensión diversidad epistémica para los documentos maestros).

Sin embargo, es otra postura la que asumen los docentes en relación con la dimensión intercultural, pues el interculturalismo y el contextualismo cultural emergen como pretensión a la diversidad en la búsqueda de la conservación de los acervos culturales, el dialogismo entre los conocimientos propios y científicos, el desarrollo de aprendizajes contextualizados, los significados y los contextos culturales. Además, ponen como tema de reflexión aspectos como la hegemonía del conocimiento, el diferenciamiento cultural, el desconocimiento de las realidades culturales y la estandarización del conocimiento.

Como consideración al estado actual, es necesario posicionar una formación docente más inclusiva conforme a las demandas de la sociedad que están enmarcadas en el contexto de nuestra nación. Esto nos orienta hacia la coexistencia cultural a través del diálogo y de la interacción, es decir, se busca comprender la importancia del conocimiento científico en el desarrollo de la humanidad sin desconocer las realidades locales y sus saberes propios. Es una apuesta que, sin duda, la escuela tendrá que afrontar en búsqueda de la promoción de sinergias que favorezcan la interacción entre los diferentes agentes educativos y sociales, para viabilizar la democratización del saber y el establecimiento de espacios de 
consensos y negociación que posibiliten la construcción de un conocimiento escolar integral.

\section{Referencias}

Adúriz, A. (2010). Aproximaciones histórico-epistemológicas para la enseñanza de conceptos disciplinares. EDUCyT, 1(1), 107-126.

Bhabha, H. (2002). El lugar de la cultura: el compromiso con la teoría. Manantial. https://asodea.files.wordpress.com/2009/o9/bhabha-homi-el-lugar-de-lacultura.pdf

Cobern, W. y Loving, C. (2001). Defining "science" in a multicultural world: implications for science education. Science Education, 85(1), 50-67.

Congreso de la República de Colombia. (1992). Ley 30. Por la cual se organiza el servicio público de la Educación Superior. Diario Oficial n. ${ }^{\circ}$ 40700. http://www.suinjuriscol.gov.co/viewDocument.asp? ruta=Leyes $/ 1586969$

Congreso de la República de Colombia. (1994, 8 de febrero). Ley 115. Por la cual se expide la Ley General de Educación. Diario Oficial n. ${ }^{\circ} 41214$. http://www.secretariasenado.gov.co/senado/basedoc/ley 0115 1994.htmlEssomb a, M. (2006). Liderar escuelas interculturales e inclusivas. Equipos directivos y profesorado ante la diversidad cultural y la inmigración. Graó.

De Sousa Santos, B. (2009). Una epistemología del sur. La reinvención del conocimiento y la emancipación social. Clacso.

El-Hani, C., y Bizzo, N. (1999). Formas de construtivismo: Teoria da mudança conceitual e construtivismo contextual. En A. Moreira, y F. Ostermann, Atas do II Encontro Nacional de Pesquisa em Educação em Ciências. http://www.abrapecnet.org.br/enpec/ii-enpec/index.html

Garay, F. (2011). Perspectivas de historia y contexto cultural en la enseñanza de las ciencias: discusiones para los procesos de enseñanza y aprendizaje. Ciência \& Educação, 17(1), 51-62. https://doi.org/10.1590/S1516-73132011000100004

Análisis

ISSN: 0120-8454 | e-ISSN: 2145-9169 | DOI: https://doi.org/10.15332/21459169

Vol. 53 N.0 98 | enero-junio de 2021 
García, N. (2004). Diferentes, desiguales y desconectados. Mapas de la Interculturalidad. Gedisa.

Geelan, D. (1997). Epistemological anarchy and the many forms of constructivism. Science y Education, (6), 15-28. https://doi.org/10.1023/A:1017991331853

Gurgel, M. (2003). Por um enfoque sociocultural da educação das Ciências Experimentais. Revista Electrónica de Enseñanza de las Ciencias, 2(3), 254-262. http://reec.uvigo.es/volumenes/volumen2/REEC 2 3 3 3.pdf

Guido, S., García, D., Lara, G., Jutinico, M., Benavidez, A., Delgadillo, I., Sandoval, B. y Bonilla H. (2013). Experiencias de educación indígena en Colombia: entre prácticas pedagógicas y políticas para la educación de grupos étnicos. Universidad Pedagógica Nacional CIUP. http://biblioteca.clacso.edu.ar/Colombia/desupn/20160601014243/Experienciaseducacionindigena.pdf

Guba, E. G., y Lincoln, Y. S. (1994). Competing paradigms in qualitative research. en N. K. Denzin y Y. S. Lincoln (eds.), Handbook of qualitative research (pp. 105-117). Sage Publications.

Gutiérrez de Pineda, V. (1975). Familia y Cultura en Colombia. Bogotá: Instituto Colombiano de Cultura. Colcultura.

Gutiérrez, I., Peralta, H., y Fuentes, H. (2018). Cultura científica y cultura científico investigativa. Humanidades Médicas, 18(1), 8-19.

Hongming, M. (2009). Chinese secondary school science teachers understanding of the Nature of Science Emerging from their views of nature. Research in Science Education, 39(5), 701-724. https://doi.org/10.1007/ s11165-008-9100-2

Kawagley, A., Norril-Tull, D. y Norris-Tull, R. (1998). The indigenous worldview of Yupiang culture: Its scientific nature and relevance to the practice and teaching of science. Journal of Research in Science Teaching, 35(2), 133-144. https://doi.org/10.1002/(SICI)1098-2736(199802)3.5:2<133::AIDTEA4>3.0.CO;2-T

Análisis

ISSN: 0120-8454 | e-ISSN: 2145-9169 | DOI: https://doi.org/10.15332/21459169

Vol. 53 N.o 98 | enero-junio de 2021 
Lopes, A. (2008). Articulaciones en las políticas de currículo. Perfiles Educativos, $30(120), 63-78$.

Loughran, J., Mulhall, P., y Berry, A. (2004). In search of pedagogical content knowledge in science: developing ways of articulating and documenting professional practice. Journal of Research in Science Teaching, 41(4), 370-391.

Martínez, C. (2017). Ser maestro de Ciencias. Productor de conocimiento profesional y de conocimiento escolar. Universidad Distrital Francisco José de Caldas.

Martínez, C., y Molina, A. (2011). La especificidad del conocimiento profesional y del conocimiento escolar en las clases de ciencias: algunas relaciones con la cultura. Revista EDUCyt, 2(2), 35-57.

Martinez, C., y Rivero, A. (2005). Algunos aspectos a considerar en una propuesta de conocimiento escolar desde una perspectiva compleja. Reflexiones en torno a un estudio de caso en las clases de ciencias. Revista Enseñanza de las Ciencias, 1(6),. http://hdl.handle.net/11441/58334

Martínez, C., y Valbuena, E. (2013). El conocimiento profesional de los profesores de ciencias sobre el conocimiento escolar: resultados de investigación. En C. Martínez, E. Valbuena, A. Molina, y C. Martinez, Énfasis Libros de los énfaiss del Doctorado interinstitucional de educación (pp. 174-181). Universidad Distrital Francisco José de Caldas.

Ministerio de Educación Nacional. (2019, 25 de julio). Decreto 1330. Por el cual se sustituye el Capítulo 2 y se suprime el Capítulo 7 del Título 3 de la Parte 5 del Libro 2 del Decreto 1075 de 2015 -Único Reglamentario del Sector Educación. https://www.mineducacion.gov.co/1759/w3-article-387348.html? noredirect=1

Molina, A., El-Hani, N., Sepulveda, C., López, D., Mojica, L., y Espitia, M. (2004).

Enfoques culturales en investigaciones acerca de la enseñanza, el aprendizaje los textos escolares en la evolución de la vida. Cuadrenos de investigación(4), 9-33.

Molina, A. (2010). Una relación urgente: Enseñanza de las ciencias y contexto cultural. EDUCyT, 1(1), 45-58.

Análisis

ISSN: 0120-8454 | e-ISSN: 2145-9169 | DOI: https://doi.org/10.15332/21459169

Vol. 53 N.o 98 | enero-junio de 2021 
Molina, A., y Utges, G. (2011). Diversidad cultural, concepciones de los profesores y los ámbitos de sus prácticas. Dos estudios de caso. Revista de Enseñanza de la Física, 24(2), 2-26. https://revistas.unc.edu.ar/index.php/revistaEF/article/view/8168

Molina, A., Martinez, C., Mosquera, C., y Mojica, L. (2009). Diversidad cultural e implicaciones en la enseñanza de las ciencias: reflexiones y avances. Revista Colombiana de educación (56), 103-128. https://doi.org/10.17227/01203916.7582

Molina , A. y Mojica, L. (2013). Enseñanza como puente entre conocimientos científicos escolares y conocimientos ecológicos tradicionales. Magis - Revista Internacional de Investigación en Educación, 6(12), 37-53.

https://doi.org/10.11144/Javeriana.m6-12.ecpe

Molina, A., Mosquera , C., Utges, G., Mojica, L., Cifuentes, C., Reyes , D., Martinez, C. y Pedreros R. (2014). Concepciones de los profesores sobre el fenómeno de la diversidad cultural y sus complicaciones en la enseñanza de las ciencias (Vol. 6). Universidad Distrital Francisco José de Caldas.

Núñez, I. (2009). La adaptación del currículo escolar a la diversidad cultural. Revista Iberoamericana de Educación, 49(2). https://doi.org/10.35362/rie4922102

Ogawa, M. (1995). Science education in a multiscience perspective. Science Education 79(5), 583-593. https://doi.org/10.1002/sce.3730790507

Porlan, A., Rivero, G., y Martin del Pozo, R. (1998). Conocimiento profesional y epistemología de los profesores II, estudios empiricos y conclusiones. Enseñanza de las ciencias: revista de investigación y experiencias didácticas, 16(2), 271-288. https://www.raco.cat/index.php/Ensenanza/article/view/21534

Pulido, G. (2009). Violencia epistémica y descolonización del conocimiento. Sociocriticism, 24(1-2), 173-201.

Rodríguez, L., y Molina, A. (2012). Pensamiento profesional en formación y relaciones de saberes. Revista EDUCyt, Extraordinario, 223-231.

Sánchez-Arteaga, J., Sepúlveda, C.y El-Hani, C. (2013). Racismo científico, procesos de alterización y enseñanza de ciencias. Magis, revista internacional de investigación en educación, 6(12), 55-67. https://doi.org/10.11144/Javeriana.m6-12.rcpa

Análisis

ISSN: 0120-8454 | e-ISSN: 2145-9169 | DOI: https://doi.org/10.15332/21459169

Vol. 53 N.o 98 | enero-junio de 2021 
Sepúlveda, C. y El-Hani, C. (2004). Quando visões de mundo se encontram: Religião e ciência na trajetória de formação de alunos protestantes de uma Licenciatura em Ciências Biológicas. Investigações em Ensino de Ciências, 9(2), 137-175.

Siegel, H. (1997). Science education: multicultural and universal. Interchange, (28), 97108. https://doi.org/10.1023/A:1007314420384

Southerland, S. (2000). Epistemic Universalism and shortcomings of curricular multicultural Science Education. Science \& Education, 9(3), 289-307.

https://doi.org/10.1023/A:1008676109903

Uribe, M. (2019). Concepciones y prácticas de profesores de ciencias en formación inicial, en realción al enfoque intercultural en la enseñanza de las ciencias. Un estudio en el contexto colombiano [tesis doctoral]. Universidad Distrital, Bogotá.

Valderrama, D. (2016). Diálogo entre conhecimentos científicos escolares e tradicionais em aulas de ciências naturais: intervenção e pesquisa na comunidade de taganga (magdalenacolômbia) [tesis de doctorado, Universidade Federal da Bahia, Salvador, Brasil]. Repositório UFBA.

https://repositorio.ufba.br/ri/handle/ri/24734

Vázquez, A., Acevedo, M., Manassero, A. yy Acevedo, P. (2001). Cuatro paradigmas básicos en la naturaleza de las ciencias. Argumentos de Razón Técnica, (4), $135-176$.

Walsh, C. (2004). Pensamiento crítico y matriz (de) colonial. Editorial Abya Yala.

Análisis

ISSN: 0120-8454 | e-ISSN: 2145-9169 | DOI: https://doi.org/10.15332/21459169

Vol. 53 N.0 98 | enero-junio de 2021 